\title{
Characterisation of drug delivery vehicles using atomic force microscopy: current status
}

James R. Smith, ${ }^{1, *}$ Temidayo O.B. Olusanya ${ }^{2}$ and Dimitrios A. Lamprou ${ }^{3}$

${ }^{1}$ School of Pharmacy and Biomedical Sciences, University of Portsmouth, St Michael's Building, White Swan Road, Portsmouth PO1 2DT, UK

${ }^{2}$ Department of Pharmaceutics, Faculty of Applied Sciences, University of Sunderland, City Campus, Sunderland, Tyne and Wear SR1 3SD, UK

${ }^{3}$ School of Pharmacy, Queen's University Belfast, 97 Lisburn Road, Medical Biology Centre, Belfast BT9 $7 B L, U K$

*For correspondence: email: james.smith@port.ac.uk, tel: +44(0) 239284 2556, fax: +44(0) 239284 3565

ORCiD:

James R. Smith

0000-0001-8805-3788

Temidayo O.B. Olusanya

0000-0002-3565-2442

Dimitrios A. Lamprou

0000-0002-8740-1661

\section{Abstract}

Introduction: The field of nanomedicine, utilising nano-sized vehicles (nanoparticles and nanofibres) for targeted local drug delivery, has a promising future. This is dependent on the ability to analyse the chemical and physical properties of these drug carriers at the nanoscale and hence atomic force microscopy (AFM), a high-resolution imaging and local force-measurement technique, is ideally suited.

Areas covered: Following a brief introduction to the technique, the review describes how AFM has been used in selected publications from 2015-2018 to characterise nanoparticles and nanofibers as drug delivery vehicles. These sections are ordered into areas of increasing AFM complexity: imaging/particle sizing, surface roughness/quantitative analysis of images and analysis of force curves (to extract nanoindentation and adhesion data).

Expert opinion: AFM imaging/sizing is used extensively for the characterisation of nanoparticle and nanofibre drug delivery vehicles, with surface roughness and nanomechanical/adhesion data acquisition being less common. The field is progressing into combining AFM with other techniques, notably SEM, ToF-SIMS, Raman, Confocal and UV. Current limitations include a $50 \mathrm{~nm}$ resolution limit of nanoparticles imaged within live cells and AFM tip-induced activation of cytoskeleton proteins. Following drug release real-time with AFM-spectroscopic techniques and studying drug interactions on cell receptors appear to be on the horizon.

Key words: Atomic Force microscopy; AFM; drug delivery; drug delivery vehicles; review 


\section{Article Highlights}

- Atomic force microscopy (AFM), a high-resolution imaging and local force measurement technique, is becoming increasing established as a tool for characterising drug delivery vehicles.

- The majority of AFM studies of nanoparticles and nanofibres are focused on imaging and particle sizing, the latter of which is in close-agreement with measurements obtained from dynamic light scattering and electron microscopy.

- Surface roughness and data have been obtained from AFM images of nano-sized drug delivery systems; the acquisition of nanomechanical properties (nanoindentation and adhesion) from AFM force curves of such systems have also been reported, although to a lesser extent.

- The field is progressing into combining AFM with other techniques (such as SEM, ToF-SIMS, Raman, Confocal and UV). Many of these promise the potential to follow drug release realtime and for studying drug interactions on cell receptors.

This box summarises key points contained in the article.

\section{Introduction}

Progress in drug design has led to the development of new peptides, proteins and drug molecules that can be used to treat a variety of diseases. However, the limited ability to selectively deliver these molecules, at well-defined dosing regimens and without invoking drug-resistance, remains a significant challenge. Nanomedicine is the application of nanotechnology to human healthcare for diagnosis, monitoring, treatment, prediction and prevention of diseases [1]. Nanomedicines consist of nanoparticles or nanofibres (typically with one dimension < dia. $100 \mathrm{~nm}$ ) that usually contain drugs that can be delivered to target tissues or organs [2-4]. Improved therapeutic outcomes have been demonstrated through the use of such delivery systems [5]. Methods to evaluate the effectiveness of nanomedicines, and indeed the nanotoxicological effects of nanoparticles in general $[3,6,7]$, continue to be developed. Atomic force microscopy (AFM), used in the fields of materials characterisation and life sciences [8-14], is becoming increasing established as a tool for characterising drug delivery vehicles and is the focus of this review.

AFM is the principal member of number of related scanning probe techniques that can provide highresolution imaging and/or local surface property measurements of samples/specimens [15]. The technique was developed in 1986 by Binnig et al. [16], building upon the successes of their previously invented scanning tunnelling microscope (STM), where atomic-scale imaging of metallic and semiconducting materials was established. This was achieved by scanning a small, conducting tip across a surface and measuring the tunnelling current between the two upon the application of a bias potential [17]. The desire to scan insulating materials, such as polymers and biological specimens, was the driving force for the development of the AFM [15]. Here, the force between a tip and sample is monitored rather than the acquisition of a tunnelling current. Strictly speaking, in the field of biology, STM could allow imaging of small biomolecules, proteins and DNA due to small tunnelling distances, albeit the conduction mechanism remains poorly understood [18-20].

Following a brief overview of the technique, this review aims to provide a selection of the numerous examples of how AFM is currently being used to investigate and characterise drug delivery vehicles. Publications have been chosen from the period 2015 to 2018. Our opinions on the applications and future direction in this field are included in the final section of this review. 


\subsection{Fundamentals}

In AFM, a small, sharp tip, prefabricated on a cantilever (together often referred to as a probe), is either scanned across ( $x, y$-plane) or moved perpendicular to (z-plane) a surface of interest. Depending on the type of AFM, either the probe or the sample is fixed to a piezoelectric ceramic scanner. The piezoelectric crystals in the scanner change length on the application of a potential difference applied across them, with a near-linear relationship between these properties and accurate to $0.1 \AA$; this feature gives AFM its high-resolution capability, and ability to overcome the Rayleigh criterion (resolution limited to wavelength of light in optical microscopy, or wavelength of electrons in electron microscopy) [15].

A laser is reflected off the back (opposite tip side) of the cantilever and onto a photodetector via a mirror (Fig. 1). This provides a method of tracking the position of the tip. As the cantilever is deflected (in $x, y$ and $z$ planes), the laser signal falls on a different region of the photodetector; this signal is converted to a voltage. This can be used, for example, to move the scanner (sample or tip), relieving the deflection on the cantilever, for example, depending on the acquisition mode. This is often referred to as the feedback (loop) circuit, with scanners being referred to as open- or closed-loop depending on their linearity of movement.

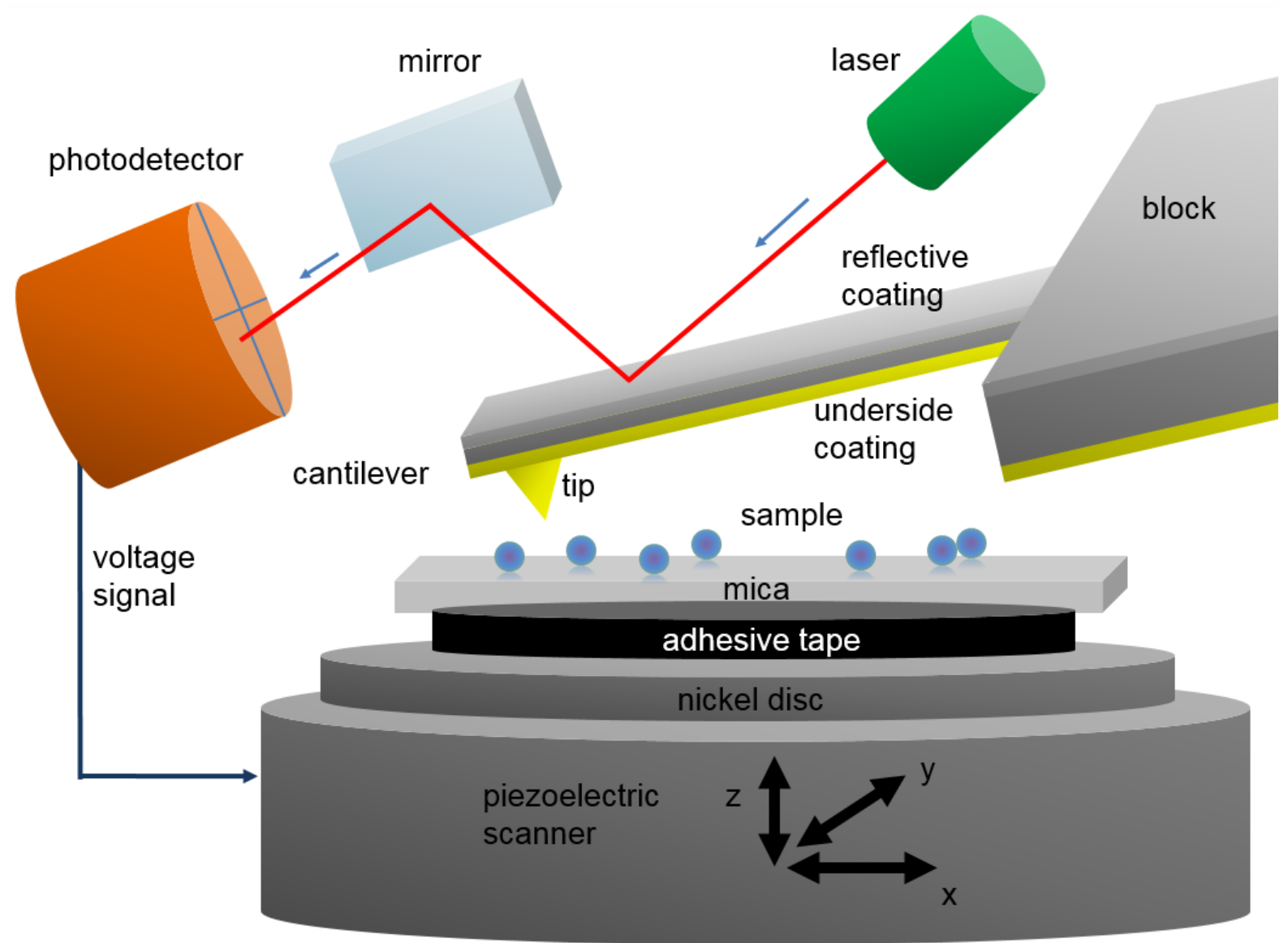

Figure 1. Schematic of the main components of a typical AFM, with particles on a mica surface.

AFM requires minimal sample preparation and can be used in a number of operating modes, although is not confined to topographical imaging. The simplest mode is known as contact mode, where the tip 
just touches the sample and there is a small deflection on the cantilever as the probe scans across the surface building up the image [15]. The applied voltage through the z-piezo to maintain the sample cantilever deflection is used as the z-component ( $z$-scale) in the resultant topography image. A problem with this mode is that lateral forces can move loosely adsorbed or delicate/soft structures on the surface, such as DNA, and so Tapping Mode ${ }^{\circledR}$ or non-contact AFM modes are preferred. In Tapping Mode ${ }^{\circledR}$, as the name suggests, the probe is vibrated vertically at its resonant frequency whilst scanning the surface. The cantilever deflection is monitored when the tip touches the surface, but the probe is moved when the tip and sample are not in contact, thus significantly reducing the later forces. Noncontact mode is similar, although no tip-sample contact is made. Instrument manufacturers tend to have their own trade mark names for some modes, such as Torsional Resonance (TR) Mode ${ }^{\circledR}$ [21], PeakForce Tapping ${ }^{\circledR}$ (PFT) and PeakForce Quantitative Nanomechanical Mapping (QNM ${ }^{\circledR}$ ) [22]. In addition to topography imaging, frictional [23-25], magnetic (magnetic force microscopy, MFM), adhesion and compression forces can be measured and mapped; the latter two achieved by pulling the probe away from or pushing it into the surface. These approaches have been developed, for example, by attaching a ligand to the probe and mapping receptor-binding sites on cell surfaces, with a lateral resolution of a few nanometres, whilst simultaneously acquiring the topography image; this is known as topography and recognition imaging (TREC) mode [26] or single-molecule force spectroscopy (SMFS) [27]. Quantitative information is obtained from the acquired force vs. distance plot (force curve) [28-30].

There are numerous types of probes (cantilevers with integrated tips) available and selection will depend on the scanning mode and application. The most appropriate tip for the sample must be selected: sharp tips give good resolution on rigid samples but can penetrate soft regions of a sample. The tip can be sharp with a radius $<2 \mathrm{~nm}$ or blunt, such as having an attached $500 \mu \mathrm{m}$ dia. microbead; the latter are usually mounted on "tipless cantilevers". Other factors that must be decided include: the tip material (important if the tip will be chemically functionalised), the length of the cantilever, the flexibility (spring constant) of the cantilever and the force applied to the sample by the tip.

Contact mode probes tend to be made from silicon nitride due to the material being hard wearing. Tapping mode and non-contact mode tips are usually comprised of silicon since it is stiff and provides cantilever spring constants in the relevant range. The tip profile can have various profiles (aspect ratios) depending on the nature of the surface to be explored; for example, if the surface has features sharper than the tip profile, artefacts can result and so a sharpened (high aspect ratio, etched) tip would be required [31].

Cantilevers may even be tip-less, if a material is be attached and used as a tip; this maybe to investigate the required tip-sample force interactions with relevant chemistry/biology [32], or to provide a sharp tip (e.g., by the attachment of carbon nanotubes) [33]. The top and/or bottom surface of the probe may be coated. Top coatings (laser side) are to make the cantilever more reflecting, and are often made of aluminium or gold. Bottom surfaces may be coated with gold, via a titanium adhesion layer, to enable self-assembled monolayers to be grafted or other surface modification useful in chemical force microscopy (CFM) [34-36]. Cantilevers can also be functionalised with proteins/fibronectins to investigate the behaviour on polymers in aqueous solutions, which will provide information on the potential of new materials to be used in human body (e.g., molecular interactions) [37].

Other related probe techniques include electrochemical AFM (EC-AFM) [38], electrostatic force microscopy (EFM) [39], kelvin probe force microscopy (KPFM) [40], photoconductive AFM (pcAFM) [41], scanning capacitance microscopy (SCM) [42], surface potential microscopy (SPoM) [43], scanning spreading resistance microscopy (SSRM) [44] and scanning thermal microscopy (SThM) [45]. 


\section{Application of AFM in drug delivery vehicle characterisation}

There are a vast array of nanosized carriers for drug delivery, including liposomes/micelles, polymers systems, porous silica, magnetic materials, graphene and mesoporous carbon nanospheres, that can take the form of particles, rods, tubes or sheets. Nanocarriers can help deliver drugs with poor aqueous solubility, low permeability, and extensive first pass metabolism. There are a number of release-type mechanisms, such as rapid, delayed, slow, pulsatile, local, and targeted drug release. Ideally, targeted drug delivery can improve the therapeutic response and maximise drug concentration to the target site. The drug release can be into a tissue or even within cells. Intracellular release is an important goal for anti-cancer drugs which often target processes in the nucleus (e.g., cyclophosphamide's active metabolite causes deleterious DNA crosslinking).

In this section, we summarise a variety of publications that have used AFM to characterise nanoparticles and nanofibres. The subsection on nanoparticles has been subdivided into groups of increasing AFM complexity: imaging, surface roughness (quantitative analysis from the images), and analysis of data/images from force vs. distance curves (nano-hardness, adhesion etc).

\subsection{Nanoparticles}

Nanoparticles used in drug delivery applications (typically $<200-500 \mathrm{~nm}$ ) usually comprise of nanospheres, nanocapsules and nanosized emulsions [46]. Nanoparticles harness the opportunities to make drug delivery more precise and to improve other characteristics such as their therapeutic index. They show promise as drug carriers due to their variable size, shape, porosity and surface properties $[47,48]$ and these parameters also have an important role to play in the in vivo biodistribution. For characterising such particles, AFM has been used for confirming shape (different shaped nanoparticles can affect transport pathways, degradation and targeting), size, surface roughness, surface charge (known to affect cellular uptake) and to a lesser degree nanomechanical/adhesion properties. These aspects are considered below.

\subsubsection{Imaging and particle sizing}

Eaton et al. directly compared nanoparticle size measurements obtained using AFM, SEM, TEM and dynamic light scattering [49]. The optimal suitability of each technique was dependent on sample type and size; for example, the metal coating of nanoparticles required for SEM had a $14 \mathrm{~nm}$ thickness and thus introduced a significant error when examining small nanoparticles. The authors did note that higher throughput measurements of particle size were achievable from TEM compared with AFM. Placzek \& Kosela reviewed and compared the use of a range of microscopy methods for the analysis of submission phospholipid dispersions, particularly with reference to drug delivery systems [46]. Particle sizing and physical properties measurements were emphasised when discussing AFM examples. Bazylińska used AFM imaging (TappingMode ${ }^{\circledR}$, TEM and DLS to characterise PEG-ylated nanocarriers, produced from a double emulsion process, that encapsulated both DNA (hydrophilic and a biomolecule example) and a hydrophobic thiazole orange dye [50]; different polymer stabilising agents were investigated (Fig. 2). Particle size data from each technique were comparable. TEM showed the core shell morphology, with the darkest region corresponding to a denser polymeric/PEGylated corona (Fig. 2a), and AFM showed an absence of enhanced aggregation (for all nanocarriers) investigated. Ramezanpour et al. reviewed computational and experimental approaches for investigating nanoparticle-based drug delivery systems [51]. Nanoscale vertical resolution of $0.01 \mathrm{~nm}$ is noted for AFM measurements, with particle size, dispersity, shape and surface morphology complementing the same properties obtained by SEM and TEM. Watanabe et al. used AFM to measure particle diameters of AmBisome, an antimycotic nanomedicine containing amphotericin B, as a function of methanol dilution and $\mathrm{pH}$ and to compare with values obtained from dynamic light 
scattering results [3]. AFM allowed such measurements to be performed that were not dependent on viscosity and so were in more accurate than DLS measurements, particularly at ca. $100 \mathrm{~nm}$. Zhang et al. produced intestinal mucous-penetrating core-shell nanocomplexes by functionally mimicking the surface of a virus [52]; TappingMode ${ }^{\circledR}$ AFM showed the nanocomplexes were spherical or sub spherical, with the coating process increasing the particle size from 100 to $300 \mathrm{~nm}$, in agreement with DLS results. Single and double emulsion poly(lactic-co-glycolic acid) (PLGA) nanoparticles encapsulating an AKT/PDK1 inhibitor (PHT-427) for targeting pancreatic tumours have been imaged using Tapping mode ${ }^{\circledR}$ AFM, which confirmed the expected spherical geometry [53]. TappingMode ${ }^{\circledR}$ AFM has also been used to image nanoparticles formed from poly(lactic acid) and alkylglycerylmodified dextran designed to carry drugs across the blood-brain-barrier [54].

(a)

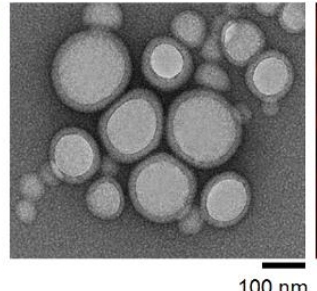

(b)

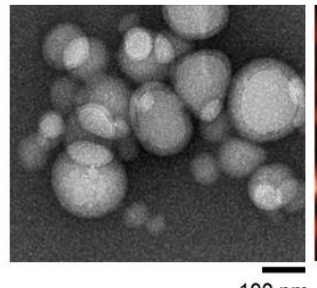

(c)

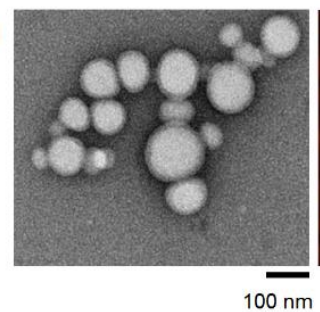

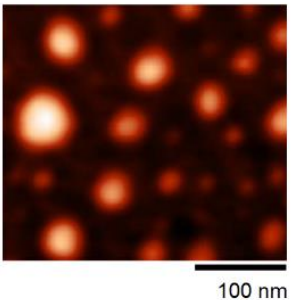
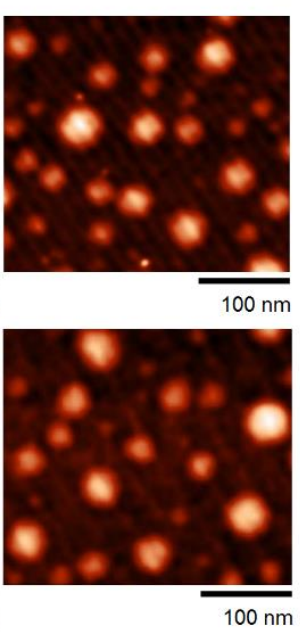
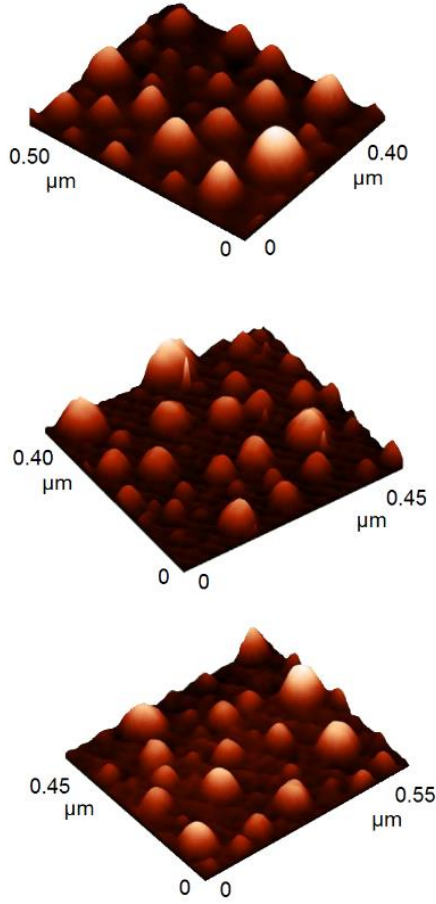
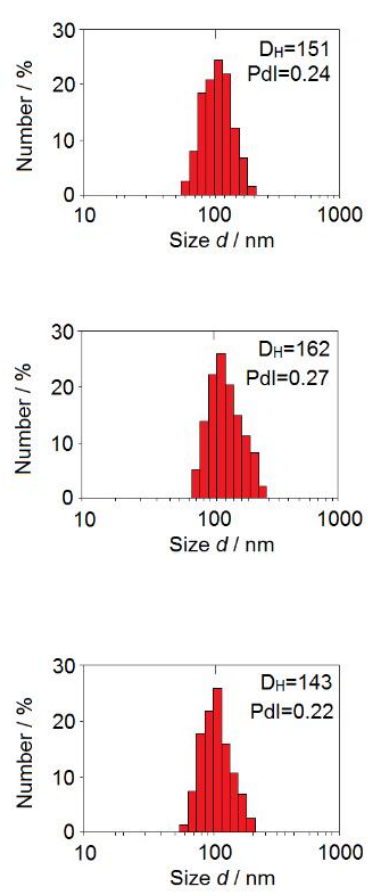

Figure 2. Example TEM and AFM images (2D and 3D-rendition) and DLS size distribution graphs (left-to-right) of DNA and hydrophobic thiazole orange-co-loaded nanocarriers stabilised by Cremophor A25 with (a) poly(ethylene glycol) methyl ether-block-poly(D,L-lactide) (PEG-PDLLA), (b) PEG-PCL, and (c) PEG-PLGA polymeric shell; $\mathrm{D}_{H}=$ mean diameter $(\mathrm{nm}) ; \mathrm{Pdl}=$ polydispersity index [50]. Reproduced with permission.

The size of protein nanocarriers was investigated by Ping et al. and the results compared with TEM and DLS studies [55]. The mean particle sizes were similar with all three techniques, however AFM was reported 'easier' with less processing involved and proteins around the particle formulations were more readily observable.

Masarudin et al. used AFM to analyse the morphology, size and surface topology of chitosan nanoparticles (CNPs) with diameters as small as $45 \mathrm{~nm}$ [56]. The sizes measured using AFM were slightly smaller than those from DLS studies, however this is due to dehydration of the samples, as is well reported in the literature. Using different formulation methods, aggregations of nanoparticles were observed using AFM that were not visible employing other techniques. AFM revealed nanoparticles of chitosan containing 2-oxothiazolidine-4-carboxylic acid for ocular delivery to be spherical, of uniform shape and with limited aggregation, supporting SEM investigations [57]. 
Akanda et al. used AFM to reveal the particles sizes of empty and loaded (retinoic acid, an anticancer agent) solid lipid nanoparticles (SLNs; $117.8 \pm 11.0$ and $169.8 \pm 21.0 \mathrm{~nm}$, respectively) [58]; however, these sizes were smaller than those measured using laser diffraction measurements and this was attributed to sample drying and a slight flattening effect caused by the AFM probe. Interestingly, Cai et al. found the mean diameters of polystyrene nanoparticles (for skin penetration) to be significantly less than those obtained from photon correlation spectroscopy (PCS) $(36.8 \pm 7.3,56.9 \pm 0.7 \mathrm{~nm}$, respectively), although the AFM values were considered to be more accurate due to direct interaction of the materials [59]; $\mathrm{SiO}_{2}$ nanoparticles, however, exhibited no difference in particle diameter when examined by AFM and PCS and this was attributed to variations in surface charge.

AFM and other techniques were used by Engelhardt et al. to characterise liposomes, made from tetraether lipids from the archaea Sulfolobus acidocaldarius, cholesterol and 1,2-dioleoyl-3trimethylammonium-propane [60]. The liposomes, for use as gene delivery vectors, were subsequently combined with a luciferase expressing plasmid (pCMV-luc) to produce lipoplexes. AFM images of lipoplexes revealed "onion-like" structures, where pDNA was wrapped around liposome cores with further alternating layers. AFM was used in conjunction with DLS measurement to confirm that cholesterol is required for producing well-organised and stable liposomes containing atenolol and quinine [61].

AFM has been used to investigate the efficacy of ultrasound mediated drug delivery [62]. Here, topography images of a cell surface treated with doxorubicin-loaded temperature-sensitive liposomes were acquired as a function of temperature. At $42{ }^{\circ} \mathrm{C}$ after $4 \mathrm{~h}$, squamous structures were observed that increased in severity with prolonged treatment.

Extracellular vesicles (EVs) are small $(<1 \mu \mathrm{m})$ phospholipid vesicles that enable the transport of proteins and genetic material between cells [63]. Nanoscale exosomes (EXOs) are a subcategory of EVs that originate from the endosomal system and have very small sizes (30 - $150 \mathrm{~nm}$ ) [64]. EXOs are released from cancer cells and tumour microenvironment (TME) stromal cells to promote tumourinduced immune suppression, angiogenesis and metastasis [65] and they also exhibit distinct markers for cancerous tumours, of use as early diagnostic tool [66-68]. EXOs also show promise in drug delivery of immunotherapeutic agents [69]. Parisse et al. commented on a survey by Gardiner et al. [70] that $<10 \%$ of studies characterising EVs reported the use of AFM techniques [64]. This was partly attributed to the difficulties in immobilising such particles for AFM characterisation, of which the authors then go on to overview such strategies; imaging in liquid was deemed to be most important.

Ping et al. observed particle sizes of suckerin-19 (S-19)/DNA complexes generally decreased with increasing protein/ DNA nitrogen-to-phosphorus (N/P) ratios [55]. Uncomplexed DNA were seen at a low N/P ratio (equal to one). Nanoparticles of $100-200 \mathrm{~nm}$ were able to encapsulate hydrophilic drugs to inhibit tumour growth. Imaging of DNA nanoparticles encapsulating buparlisib (BKM120; a PI3K inhibitor) in high efficiency for treatment of chronic lymphocytic leukaemia confirmed the spherical, near-monodispersed population of this material [71].

Arora et al. used AFM to image and size of cytotoxic 5-methylmellein (5-MM)-loaded bovine serum albumin nanoparticles in their investigations; $5-\mathrm{MM}$ is a secondary metabolite from Xylaria psidii [72]. AFM imaging black phosphorus nanoparticles revealed the structures to have a platelet-like form, with sizes of 100-500 nm (in agreement with dynamic light scattering measurements) and much smaller thicknesses [73]; these nanoparticles were functionalised with cisplatin and oxaliplatin and used against ovarian cancer cells. 
Paul et al. used TappingMode ${ }^{\circledR}$ AFM (topography and phase imaging) and combined AFM-confocal microscopy to image molecularly imprinted polymers based on insulin [74]; images with and without the protein were recorded. TappingMode ${ }^{\circledR}$ was also used by Fatouros et al. to produce size histograms of peptide nanovesicles and to observe their necklace-like formations on mica after quick drying in air [75]; ImageJ was used to enhance surface features.

The particle-size distribution of filtered vs. unfiltered commercially-available tattoo ink (30-600 and 40-970 nm, respectively) obtained from AFM scanning on glass was reported by Grant et al. [76]. Cryosections of skin tissue containing tattoo ink nanoparticles were also imaged using AFM and were comparable to those on glass. Dense collagen fibril networks and scar tissue from the tattooing process were also reported.

\subsubsection{Surface roughness}

Accurate characterisation of nanoscale surface roughness is important in many applications, including drug delivery applications. Surface roughness can be measured by using a number of techniques, however the most accurate technique for nanoparticles is AFM; here, height deviations from a mean height obtained from line-transects drawn across AFM images (datasets) are used; there are numerous roughness parameters available (e.g., $R_{a}, R_{q}, R_{z}, R_{\max }$ ), although the arithmetic roughness average, $R_{a}$, is the most widely used [77].

Surface roughness values were obtained from AFM images of spray-dried and spray-freeze-dried silkbased nanoparticles; the latter had much larger values ( $R_{a} 421$ c.f. $27 \mathrm{~nm}$ ) and were therefore judged more favourable for improved dispersion and enhanced aerosolisation efficiency for their use as lung cancer delivery agents (encapsulating cisplatin) [78].

Perli et al. obtained AFM images and roughness values of silver nanoparticles coated with chitosan (stabilising agent and anticoagulant) for antimicrobial applications [79]. Surface roughness (RMS) was found to decrease with increasing chitosan concentration, probably due to the formation of a uniform coating. AFM also revealed a particle diameter of ca. $160 \mathrm{~nm}$. The paper then explored imaging of the uncoated silver nanoparticles (dia. $30 \mathrm{~nm}$ ) loaded into poly( $\varepsilon$-caprolactone) scaffolds produced by electrospinning (Fig. 3). TappingMode ${ }^{\circledR}$ AFM imaging was used to support SEM and TEM imaging of silver nanoparticles for targeting A549 lung cancer cells [80]; surface topography, roughness, bearing ratio and amplitude variation data were presented. The surfaces of silk nanoparticles for use as drug delivery vehicles were imaged using AFM by Kumar \& Singh [81]; surface roughness was also assessed.

\subsubsection{Nanomechanical/adhesion properties}

Marchetti et al. reviewed the use of AFM nanoindentation measurements in virology [82]. Valuable information concerning the mechanics of capsid-genome interactions, morphological changes driving viral maturation, capsid stabilising factors and viral uncoating may all be gained, highlighting the link between mechanics and infectivity, and having nanomedicinal implications.

Reggente et al. used contact resonance AFM (CR-AFM) subsurface nanomechanical imaging to locate stiff (magnetic) nanoparticles embedded in soft biological tissue [83], opening the way for further advancements in drug delivery and nanotoxicology. In this contact mode technique, an ultrasonic transducer is mounted on the back of the sample and out-of-plane oscillations are excited; resonance frequencies of the cantilever-tip-sample system (contact resonance frequencies, CRFs), corresponding to local elastic properties, area then recorded and mapped alongside topography images. 

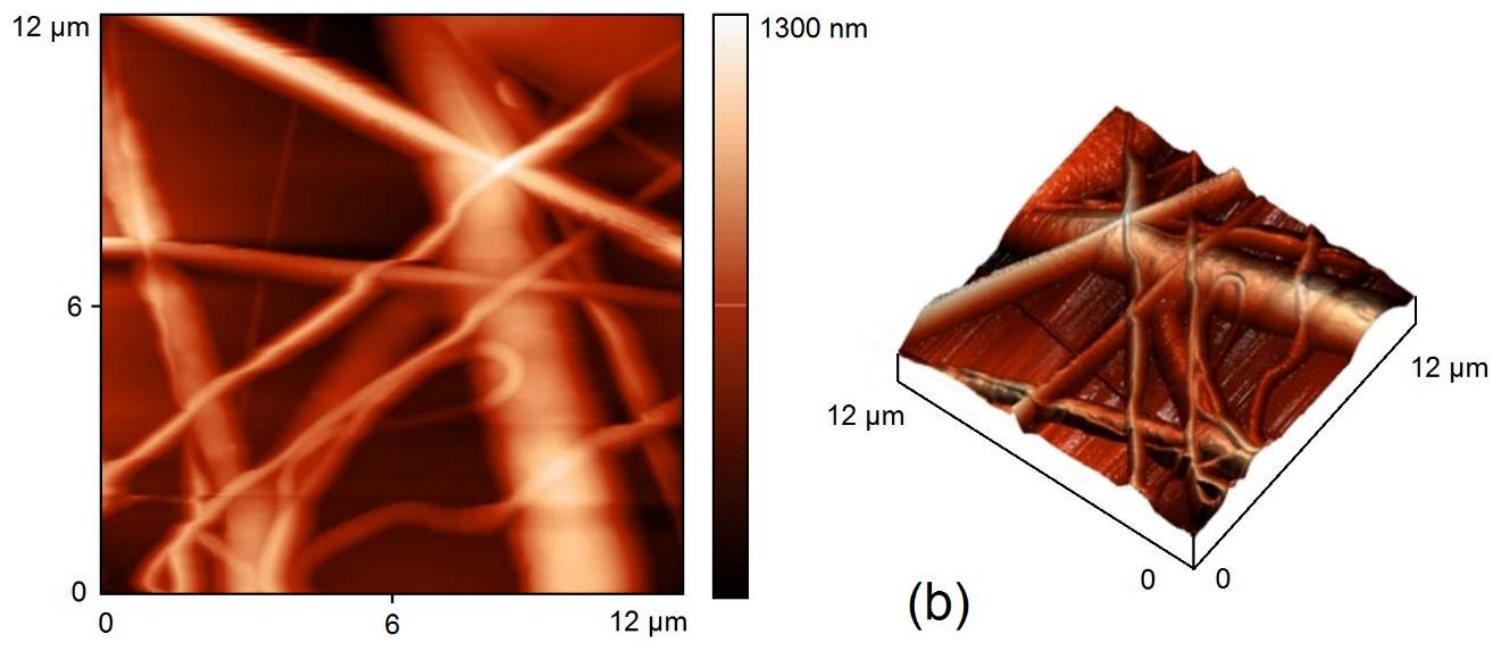

(a)
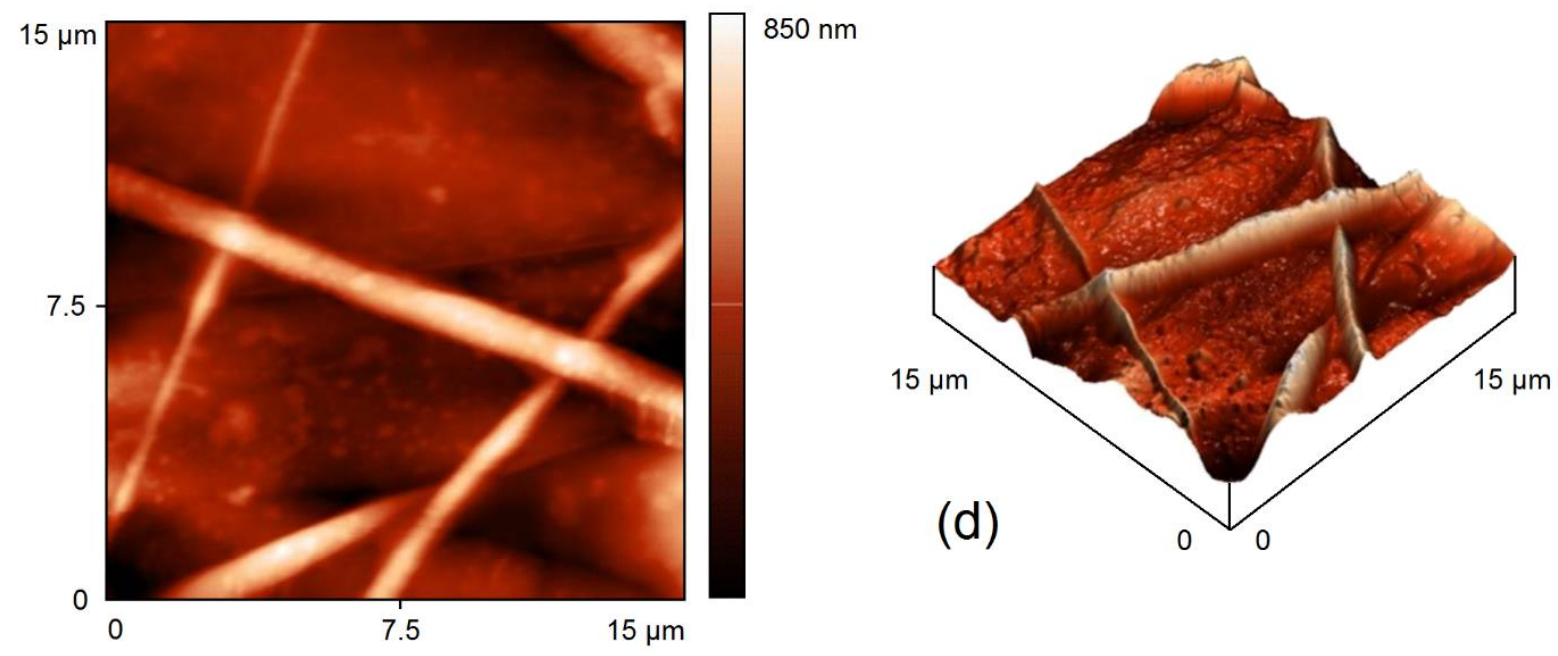

(C)

Figure 3. AFM topography images of poly( $\varepsilon$-caprolactone) scaffolds, $(a, b)$ unloaded and $(c, d)$ loaded with silver nanoparticles [79]. Reproduced with permission.

Karagkiozaki et al. reviewed the use of nanomedicine in the treatment of thrombosis [84]. Whilst AFM has been used to image platelets on carbon nanocoatings [85], and show morphological alterations of platelets on nanomaterials [86], functionalisation of AFM tips with proteins for thrombosis elucidation has not yet been realised. Individual receptors have been identified, however, using force-mapping with AFM tips functionalised with antibodies [87].

While photon and electron microscopies can offer the opportunity to image a sample in 3D, AFM is unique in being able to determine material's nanomechanical properties as well as imaging its surface and track an object over time. Mapping the nanomechanical properties (principally stiffness and adhesion) is referred in AFM as quantitative nanomechanical mapping (QNM). QNM is ideal for biological samples, and some of its many potential uses include tracking particles, diagnosing cancer, understanding cellular responses to changing conditions, and investigating adhesion. PeakForce QNM mode AFM was used by Gebril et al. to characterise their developed lipid formulations for evaluating 
mechanical properties (e.g., Young's Modulus), as well as size (Fig. 4) and surface roughness, of their nanoformulations [88]. The mechanical data clearly showed that gonadotrophin-releasing hormone conjugates had a significant effect on the lipid membrane, but not on the shape, and they were also able to see differences on the mechanical properties when a variety of lipid concentrations had been used. This was not possible with any other technique, especially for formulations that are in the nanometre-scale and with similar morphologies (e.g., spherical shape and size).
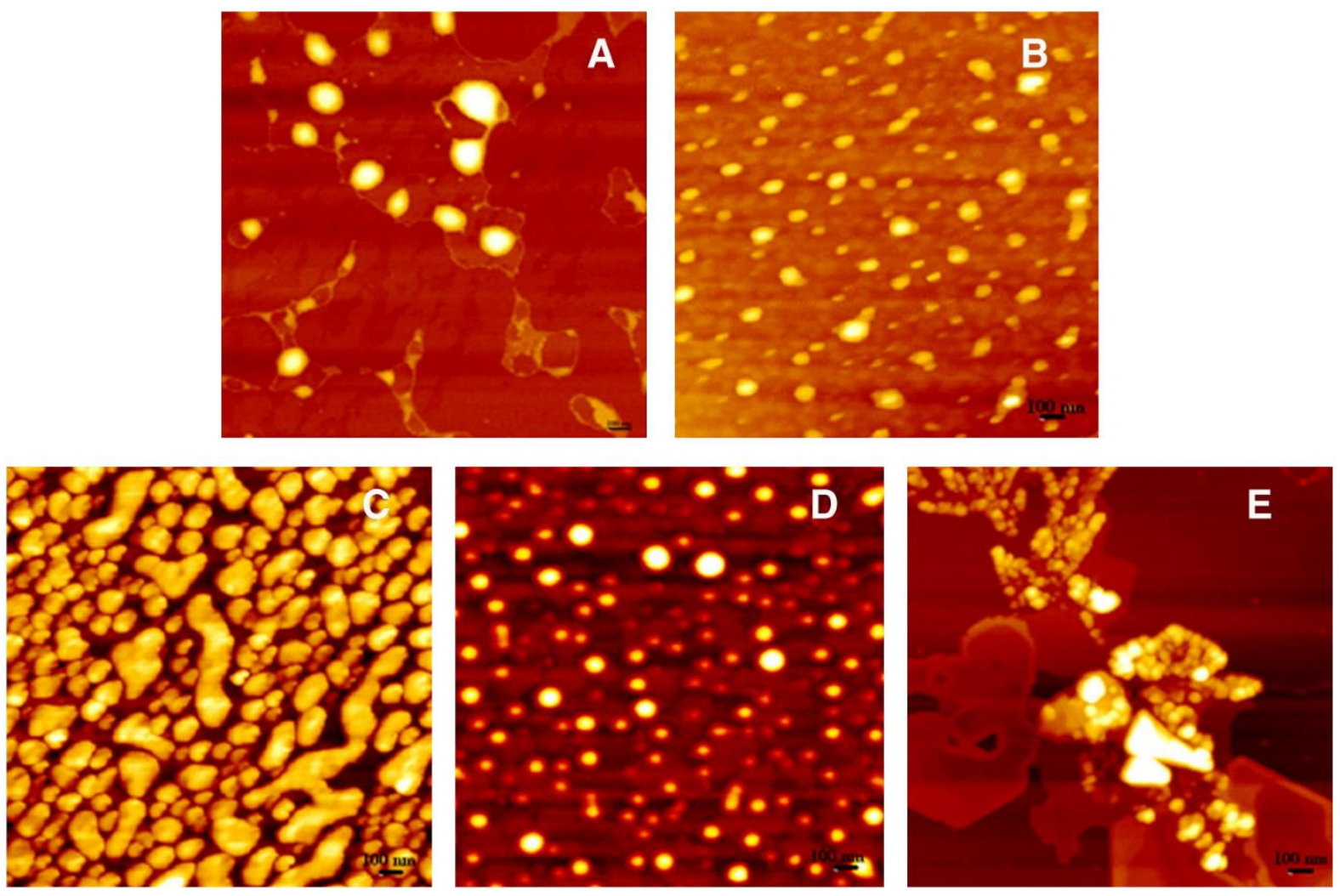

Figure 4. Representative AFM images of (a) empty bilosomes, (b) loaded bilosomes, (c) empty non-ionic surfactant vesicles (NISV), (d) loaded NSIV, and (e) loaded NSIV with xanthan gum; scale bar = $100 \mathrm{~nm}$ [88]. Reproduced with permission.

Cai et al. used AFM force measurements to demonstrate that tetracaine (a model drug) was strongly adsorbed onto a negatively-charged carboxyl-modified polystyrene nanoparticle through its methyl and amine functionalities ( 6 and 16 -fold increases, respectively, compared to a $\mathrm{CH}_{3}-\mathrm{CH}_{3}$ interaction) [89]; adhesion values to silica nanoparticles were much reduced, owing to their much lower surface potentials.

A research paper entirely focused in the detection and measurement of the viscoelastic nanomechanical properties (called contact-resonance, CR) of magnetic nanoparticles in soft biological matrices by AFM was reported by Reggente et al. (2017) [83]; CR-AFM can be used as a promising technique for subsurface imaging of nanomaterials in biological samples.

\subsection{Nanofibres}

Nanofibre mats produced from electrospinning are very attractive as delivery vehicles since they are biodegradable and biocompatible [90-92]. They are also very attractive due to their huge surface areato-volume ratio [93]. The mechanical properties and the compatibility is a key goal, which is 
dependent on the material, density, compliance and electric charge of the mesh. Topography images and roughness measurements have been obtained on electrospun nanofibres for local and sustained release of rosuvastatin and heparin for use as endovascular stents [94]. The drugs with cellulose acetate were dissolved in $\mathrm{N}, \mathrm{N}$-dimethylacetamide and acetone and electrospun onto commercial Co$\mathrm{Cr}, \mathrm{Ni}-\mathrm{Ti}$ and stainless steel stents. The surfaces and roughness values of the coatings on all these substrates were comparable. In a study of magnetic nanoparticles $\left(\mathrm{Fe}_{3} \mathrm{O}_{4}\right)$ embedded in poly(acrylonitrile)/poly(DL-lactide) electrospun fibres, AFM revealed the nanoparticles had become completely coated by the polymer to the extent that their positions along the fibres could not be ascertained [95]. Viana et al. used AFM to show the thickness, diameter and morphological differences between electrospun fibres and those also containing an antimicrobial polypeptide [96]. The authors also made note of diameter increases with respect to SEM measurements, being due to tip-sample convolution effects and/or dehydration with SEM samples (widely known phenomena).

The dynamic phase separation within electrospun fibres of poly(vinylpyrrolidone) (PVP) / hydroxypropyl methylcellulose acetate succinate hydrophilic / hydrophobic polymer blends (drug carriers) have been investigated [97]. AFM revealed nanoscale phase separation was observed for electrospun fibres whereas micron-scale separation was apparent using conventional blending methods (film casting and spin-coating), which have implications for drug delivery.

Barrientos et al. incorporated irgasan, and separately, levofloxacin (both antibacterial agents) into scaffolds [98]. AFM images showed crystals of levofloxacin on fibre surfaces, but not those of irgasan; in a related paper [99], the same drugs were incorporated with type I collagen and fibril banding on the levofloxacin-containing fibres was observed confirming the deposition of collagen (Fig. 5).

Kaur et al. produced electrospun PAN-carbon nanotube (CNT) composite nanofibres [93]. AFM scanning revealed the surfaces to have increasing roughness with increasing levels of multiwalledCNTs. Poly(L-lactide) and poly(e-caprolactone) (PCL) fibres loaded with 25-hydroxyvitamin D3 (an antibiotic precursor) have been electrospun and characterised by AFM and other techniques [100]. $\mathrm{PCL}$ fibres were smooth, but were rougher for poly(L-lactide), and more so after than encapsulation of the drug.

Mucoadhesive fibres for drug delivery were produced by electrospinning poly(ethylene oxide) and mucoadhesive polymers carboxymethylcellulose, sodium alginate and poly(acrylic acid) [101]. AFM surface roughness measurements of fibres in simulated vaginal fluid showed the polymer blend containing carboxymethylcellulose to have the best prospects.

Wali et al. prepared electrospun blends of ethyl hydroxyl ethyl cellulose (EHEC), hydrophobically modified EHEC (HM-EHEC) and poly(vinyl alcohol) from THF/water on to silicon wafers and the resultant nanofibre mats were analysed using AFM (to obtain film thickness and surface roughness) and other techniques [102]. Chlorhexidine digluconate was also incorporated into the mats. Film thickness was independent on rotation speeds, although surface roughness decreased with increasing rotation speed. These AFM measurements therefore established an optimal rotation speed (4500 $\mathrm{rpm}$ ) to achieve uniform roughness of coating in further experiments. In addition, PVA provided smoothness to the otherwise granular geometry of the HM-EHEC surface.

Dzamukova et al. used AFM imaging to examine surface-absorbed nanotubes (halloysite nanotubes with physically-adsorbed dextrin, DX-HNTs) on human lung carcinoma epithelial cells (A549) and hepatocellular carcinoma cells (Hep3b) [103]; imaging of dried cells advantageously enabled probing of solid nanotubes agglomerates through the collapsed cell membranes. DX-HNTs were internalised differently in the two cell types, which could be exploited for different therapeutic treatments. 


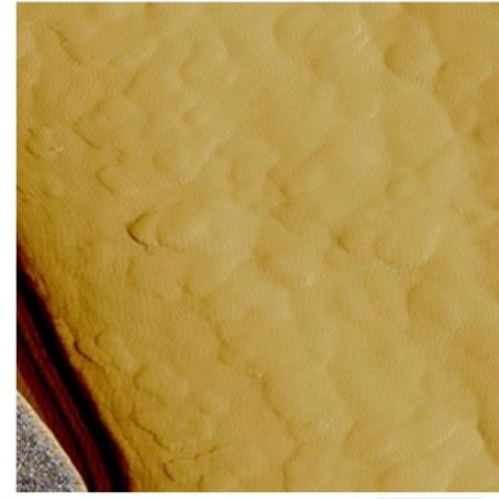

(a)

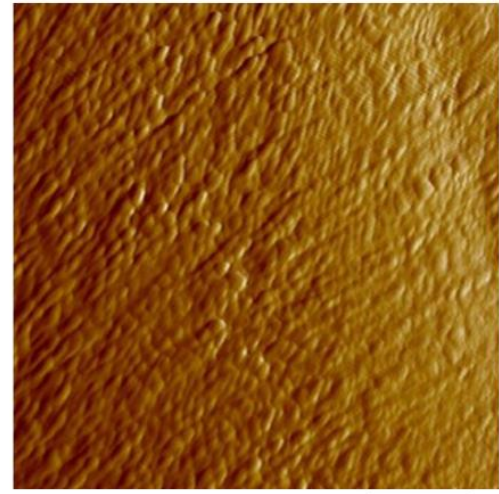

(d)

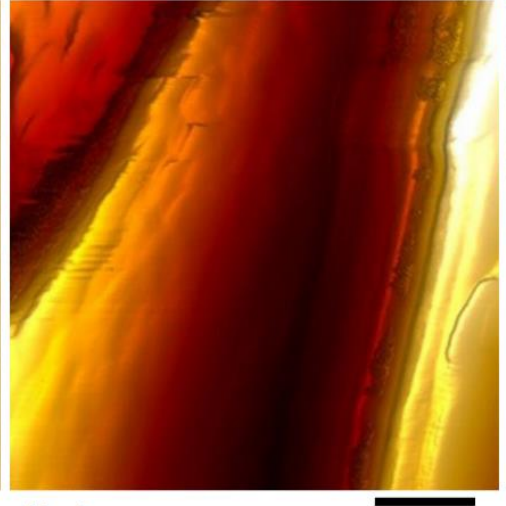

$\overline{300 \mathrm{~nm}}$

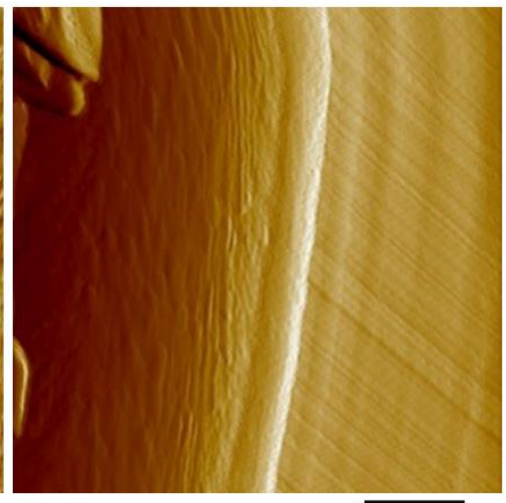

$\overline{440 \mathrm{~nm}}$

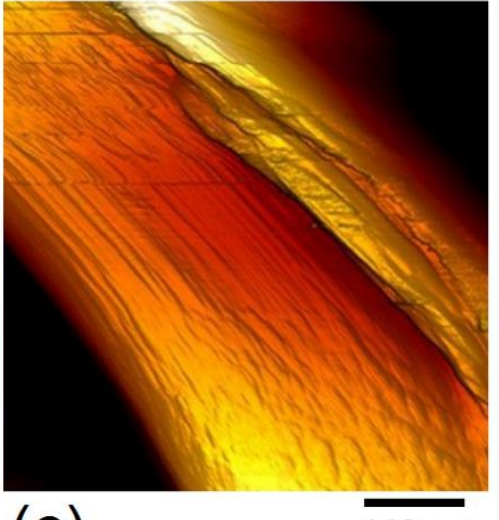

$440 \mathrm{~nm}$

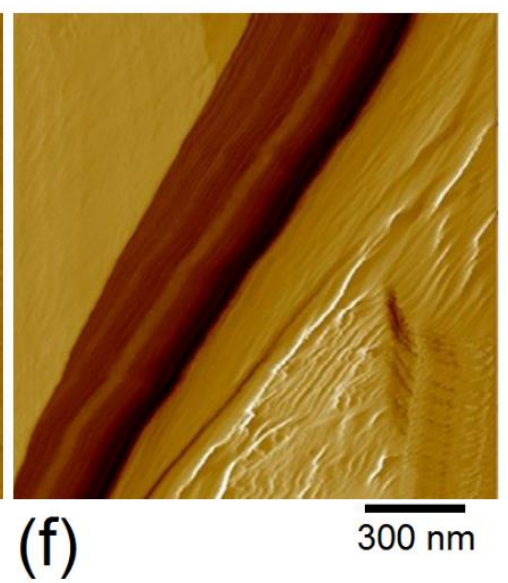

Figure 5. AFM images of electrospun nanofibres: (a) poly(lactic acid) (PLA) unloaded, (b) PLA-irgasan (IRG), (c) PLA-levofloxacin (LEVO), (d) PLA-collagen, (e) PLA-collagen-IRG, and (f) PLA-collagen-LEVO [99]. Reproduced with permission.

Mendes et al. performed AFM nanoindentation measurements to obtain the Young's Modulii of electrospun asolectin phospholipid fibres [104]. Values were $17.26 \pm 1 \mathrm{MPa}$, being stiffer than similar materials (natural cholesterol and phosphatidylcholine, respectively 0.27 and $0.03 \mathrm{MPa}$ ) but having a lower stiffness than synthetic polymers, such as PLLA, PVA and PAN ( 0.5 to $0.9 \mathrm{GPa}, 4$ to $13 \mathrm{GPa}$, and 5.72 to $26.55 \mathrm{GPa}$, respectively).

\section{Conclusions}

AFM continues to be used extensively for the characterisation of drug delivery vehicles, most of which fit broadly into the groupings of nanoparticles and nanofibres. The majority of studies present images of these drug carriers with reports of dimensions and their comparison with other techniques, such as DLS and TEM/SEM. A smaller subset of publications draw out surface roughness information from AFM images to make comparisons. The smallest subset of recent papers that report the characterisation of drug delivery vehicles using AFM (among other techniques) touch on the ability of the technique to acquire force vs. distance data, i.e., nanomechanical properties. This is unusual in that AFM is now an established, albeit still rapidly growing, technique and other fields more routinely use the nanomechanical acquisition aspects of AFM. This may reflect the difficulty, however, in obtaining such measurements from nanoparticle surfaces, especially in liquids where anchoring to suitable substrates can problematic. 


\section{Expert Opinion}

AFM is characterised by superior resolution and possible interaction mapping in the $\mathrm{pN}$ range. The technique has become essential in a variety of fields, including the characterisation of systems for drug delivery applications. Today, extensive imaging and spectroscopic techniques have been combined with AFM to provide more powerful analyses. These include SEM-AFM, 3D tomographic AFM, AFM-ToF-SIMS, AFM-Raman, AFM-Confocal Raman Microscopy, AFM-NanoIR and AFM-UV systems, among others. This is certainly an exciting time in both the development and application of AFM combined with optical imaging or/and spectroscopic techniques.

In the future, it will be possible to use AFM to more closely follow chemical reactions that could be used to investigate how drugs interact with cells or bacteria. AFM will provide the high-resolution necessary to follow these nanoscale reactions that is not currently possible. The development of advanced microelectromechanical systems (MEMS) devices will enable AFM technology to be scaled down to fit onto a chip measuring ca. $1 \mathrm{~cm}^{2}$. This would allow such devices to be placed inside the human body to enable a better understanding of chemical and particle interactions and in real-time, with particular benefits in the field of nanotoxicology.

Developments in the ability of AFM to measure electric and magnetic fields at increasingly higher resolution are also likely to be beneficial for the characterisation of nano-sized carriers, particular those that have electrical and magnetic stimuli as release mechanisms.

Currently, the resolution of AFM images of nanoparticles inside live cells is limited to $50 \mathrm{~nm}$. Mechanical measurements on living cells have an effect on microtubules or actin of the cytoskeleton, which can result in an increase in cellular stiffness. With the latest developments in AFM technology and chemistry, the study of the effect nanoparticles have on live cells is now possible and at increasingly higher resolution. Also, with the use of AFM-spectroscopic analysis, it will soon be possible to "follow" drug release inside tissues and further understand how drugs "attack" cancer cells, for example. This will be aided through the recently developed fast scanning AFM techniques, where realtime acquisition, at least for flat samples, is possible through the use of small cantilevers. Further developments in high-speed scanning will continue, combined with high-resolution imaging showing how drug molecules interact with cells.

There is an increase in the number of studies using AFM as the crucial technique, however, there is still a gap in the literature on the use of AFM to investigate adhesion mapping of cell receptors before and after the additions of drugs, and with the combination with spectroscopic techniques. This would be expected to be another future development of AFM in the field.

\section{Declaration of interest}

The authors report no conflicts of interests in relation to the preparation of this manuscript.

\section{References}

Papers of special note have been highlighted as either of interest $(\bullet)$ or of considerable interest $(\bullet \bullet)$ to readers.

1. Kim EM, Jeong HJ. Current status and future direction of nanomedicine: focus on advanced biological and medical applications. Nucl Med Mol Imaging. 2017; 51: 106-17. (doi:10.1007/s13139-016-0435-8)

2. Bobo D, Robinson KJ, Islam J, et al. Nanoparticle-based medicines: a review of FDA-approved materials and clinical trials to date. Pharm Res. 2016; 33: 2373-87. (doi:10.1007/s11095-016-1958-5) 


\section{- A good review of FDA approved nanomedicines.}

3. Watanabe A, Takagi M, Murata S, et al. Stability and drug release studies of an antimycotic nanomedicine using HPLC, dynamic light scattering and atomic force microscopy. J Pharm Biomed Anal. 2018; 148: 149-155. (doi:10.1016/j.jpba.2017.09.030)

4. Wang RB, Billone PS, Mullett WM. Nanomedicine in action: an overview of cancer nanomedicine on the market and in clinical trials. J Nanomater. 2013; 629681. (doi:10.1155/2013/629681)

5. Olusanya TOB, Ahmad RRH, Ibegbu DM, et al. Liposomal drug delivery systems and anticancer drugs. Molecules. 2018; 23: 907. (doi:10.3390/molecules23040907)

6. Pyrgiotakis G, Blattmann CO, Demokritou P. Real-time nanoparticle-cell interactions in physiological media by atomic force microscopy. ACS Sustain Chem Eng. 2014; 2: 1681-90. (doi:10.1021/sc500152g)

7. Dorobantu LS., Fallone C, Noble AJ, et al. Toxicity of silver nanoparticles against bacteria, yeast, and algae. J Nanoparticle Res 2015; 17: 172. (doi:10.1007/s11051-015-2984-7)

8. Eaton P, West P. Atomic Force Microscopy. 2010. Oxford, Oxford Univ. Press

• A highly recommended textbook for anyone wishing to learn AFM.

9. Smith JR, Larson C, Campbell SA. Recent applications of SEM and AFM for assessing topography of metal and related coatings - a review. Trans IMF. 2011; 89: 18-27. (doi:10.1179/174591910x12922367327388)

\section{- A good review on past and future of SEM and AFM topography.}

10. Zhang H, Huang JX, Wang YW, et al. Atomic force microscopy for two-dimensional materials: A tutorial review. Optics Commun. 2018; 406: 3-17. (doi:10.1016/j.optcom.2017.05.015)

\section{- A good review for understanding different AFM modes.}

11. Smith JR, Maherally Z, Higgins SC, et al. AFM observation of heightened cell periphery of high-grade glioblastoma cell lines. Bionanoscience. 2016; 6: 47-53. (doi:10.1007/s12668-015-0188-3)

12. Maherally Z, Smith JR, Ghoneim MK, et al. Silencing of CD44 in glioma leads to changes in cytoskeletal protein expression and cellular biomechanical deformation properties as measured by AFM nanoindentation. Bionanoscience. 2016; 6: 54-64. (doi:10.1007/s12668-015-0189-2)

13. Breakspear S, Smith JR, Luengo G. Effect of the covalently linked fatty acid 18-MEA on the nanotribology of hair's outermost surface. J Struct Biol. 2005; 149: 235-42. (doi:10.1016/j.jsb.2004.10.003)

14. Court S, Kerr C, de Leon CP, et al. Monitoring of zincate pre-treatment of aluminium prior to electroless nickel plating. Trans IMF. 2017; 95: 97-105. (doi:10.1080/00202967.2016.1236573)

15. Smith JR, Breakspear S, Campbell SA. AFM in surface finishing: Part I. An introduction. Trans IMF. 2003; 81: B26-9

16. Binnig G, Quate C.F, Gerber C. Atomic force microscope. Phys Rev Lett. 1986; 56: 930-3

17. Binnig G, Rohrer H, Gerber C, et al. Tunneling through a controllable vacuum gap. Appl Phys Lett. 1982; 40: $178-180$

18. Campbell SA, Smith JR, Jungblut $\mathrm{H}$, et al. Protein imaging on a semiconducting substrate: A scanning tunnelling microscopy investigation. J Electroanal Chem. 2007; 599: 313-22. (doi:10.1016/j.jelechem.2006.05.035)

19. Lewerenz HJ, Skorupska K, Smith JR, et al. Surface chemistry and electronics of semiconductornanosystem junctions II: enzyme immobilization, charge transport aspects and scanning probe microscopy imaging. J Solid State Electrochem. 2009; 13: 195-203. (doi:10.1007/s10008-008-0641-0) 
20. Skorupska K, Lewerenz HJ, Smith JR, et al. Macromolecule-semiconductor interfaces: From enzyme immobilization to photoelectrocatalytical applications. J Electroanal Chem. 2011; 662: 169 (doi:10.1016/j.jelechem.2011.05.020)

21. Song YX, Bhushan B. Dynamic analysis of torsional resonance mode of atomic force microscopy and its application to in-plane surface property extraction. Microsystem Technol Micro Nanosys Inform Storage Proc Sys. 2006; 12: 219-30. (doi:10.1007/s00542-005-0070-2)

22. Lamprou DA, Venkatpurwar V, Kumar M. Atomic force microscopy images label-free, drug encapsulated nanoparticles in vivo and detects difference in tissue mechanical properties of treated and untreated: A tip for nanotoxicology. PLoS ONE. 2013; 8: e64490. (doi:10.1371/journal.pone.0064490)

\section{$\bullet \bullet$ A useful source for using AFM to understand the cytotoxicity of nanoparticles in vivo.}

23. Breakspear S, Smith JR, Nevell TG, et al. Friction coefficient mapping using the atomic force microscope. Surface Interface Anal. 2004; 36: 1330-4. (doi:10.1002/sia.1914)

24. Smith JR, Tsibouklis J, Nevell TG, et al. AFM friction and adhesion mapping of the substructures of human hair cuticles. Appl Surface Sci. 2013; 285: 638-644. (doi:10.1016/j.apsusc.2013.08.104)

25. Breakspear S, Smith JR, Campbell SA. AFM in surface finishing: Part III. Lateral force microscopy and friction measurements. Trans IMF. 2003; 81: B68-70

26. Chtcheglova LA, Hinterdorfer P. Simultaneous AFM topography and recognition imaging at the plasma membrane of mammalian cells. Seminars Cell Develop Biol. 2018; 73: 45-56. (doi:10.1016/j.semcdb.2017.08.025)

27. Muller DJ, Helenius J, Alsteens D, et al. Force probing surfaces of living cells to molecular resolution. Nature Chem Biol. 2009; 5: 383-90. (doi:10.1038/nchembio.181)

28. Cappella B, Dietler G. Force-distance curves by atomic force microscopy. Surface Sci Reports. 1999; 34: 1-104. (doi:10.1016/s0167-5729(99)00003-5)

29. Butt HJ, Cappella B, Kappl M. Force measurements with the atomic force microscope: Technique, interpretation and applications. Surface Sci Reports. 2005; 59: 1-152. (doi:10.1016/j.surfrep.2005.08.003)

30. Smith JR, Breakspear S, Fletcher RJR, et al. AFM in surface finishing: Part IV. Force-distance curves. Trans IMF. 2005; 83: 63-7. (doi:10.1179/002029605×38979)

31. Golek F, Mazur P, Ryszka Z, et al. AFM image artifacts. Appl Surface Sci. 2014; $304: 11-9$. (doi:10.1016/j.apsusc.2014.01.149)

32. Sikora AE, Smith JR, Campbell SA, et al. AFM protein-protein interactions within the EcoR124I molecular motor. Soft Matter. 2012; 8: 6358-63. (doi:10.1039/c2sm07213k)

33. Slattery AD, Shearer CJ, Shapter JG, et al. Solution based methods for the fabrication of carbon nanotube modified atomic force microscopy probes. Nanomaterials. 2017; 7: 346. (doi:10.3390/nano7110346)

34. Ito T, Grabowska I, Ibrahim S. Chemical-force microscopy for materials characterization. TrAC-Trends Anal Chem. 2010; 29: 225-33. (doi:10.1016/j.trac.2009.12.008)

\section{- A useful paper describing chemical force microscopy.}

35. Lamprou DA, Smith JR, Nevell TG, et al. Self-assembled alkanethiol structures on gold: A further insight into the origins of structural rearrangement phenomena. Surface Sci. 2010; 604: 541-7. (doi:10.1016/j.susc.2009.12.022)

36. Lamprou DA, Smith JR, Nevell TG, et al. Self-assembled structures of alkanethiols on gold-coated cantilever tips and substrates for atomic force microscopy: Molecular organisation and conditions for reproducible deposition. Appl Surface Sci. 2010; 256: 1961-8. (doi:10.1016/j.apsusc.2009.10.045) 
37. Mallinson D, Cheung DL, Simionesie D, et al. Experimental and computational examination of anastellin (FnIII1c)-polymer interactions. J Biomed Mater Res Part A. 2017; 105: 737-45. (doi:10.1002/jbm.a.35949)

\section{- A good source for understanding the interactions of proteins with polymers for biomedical applications.}

38. Yivlialin R, Penconi M, Bussetti G, et al. Morphological changes of porphine films on graphite by perchloric and phosphoric electrolytes: An electrochemical-AFM study. Appl Surface Sci. 2018; 442: 501-506. (doi: 10.1016/j.apsusc.2018.02.171)

39. Konomi M, Sacha GM. Feedforward neural network methodology to characterize thin films by Electrostatic Force Microscopy. Ultramicroscopy. 2017; 182: 243-248. (doi: 10.1016/j.ultramic.2017.07.015)

40. Melitz W, Shen J, Kummel AC, et al. Kelvin probe force microscopy and its application. Surface Sci Reports. 2011; 66: 1-27. (doi: 10.1016/j.surfrep.2010.10.001)

41. Heo J, Won S. Scanning probe study on the photovoltaic characteristics of a Si solar cell by using Kelvin force microscopy and photoconductive atomic force microscopy. Thin Solid Films. 2013; 546: 353-357. (doi: 10.1016/j.tsf.2013.04.076)

42. Ligor O, Gautier B, Descamps-Mandine A, et al. Interpretation of scanning capacitance microscopy for thin oxides characterization. Thin Solid Films. 2009; 517: 6721-6725. (doi: 10.1016/j.tsf.2009.05.026)

43. Lee I, Chung E, Kweon $\mathrm{H}$, et al. Scanning surface potential microscopy of spore adhesion on surfaces. Colloid Surfaces B: Biointerfaces. 2012; 92: 271-276. (doi: 10.1016/j.colsurfb.2011.11.052)

44. Doering S, Wachowiak A, Winkler U. Scanning Spreading Resistance Microscopy analysis of locally blocked implant sites. Microelectron Eng. 2014; 122: 77-81. (doi: 10.1016/j.mee.2014.02.021)

45. Fischer H. Quantitative determination of heat conductivities by scanning thermal microscopy. Thermochim Acta. 2005; 425: 69-74. (doi:10.1016/j.tca.2004.06.005)

46. Placzek M, Kosela M. Microscopic methods in analysis of submicron phospholipid dispersions. Acta Pharm. 2016; 66: 1-22. (doi:10.1515/acph-2016-0003)

47. Zhu J, Liao L, Bian XJ, et al. pH-Controlled delivery of doxorubicin to cancer cells, based on small mesoporous carbon nanospheres. Small. 2012; 8: 2715-20. (doi:10.1002/smll.201200217)

48. Smith JR, Lamprou DA. Polymer coatings for biomedical applications: a review. Trans IMF. 2014; 92: 919. (doi:10.1179/0020296713z.000000000157)

- A detailed review describing biomedical applications of polymers for drug delivery.

49. Eaton P, Quaresma P, Soares C, et al. A direct comparison of experimental methods to measure dimensions of synthetic nanoparticles. Ultramicroscopy. 2017 ; 182 : $179-190$. (doi:10.1016/j.ultramic.2017.07.001)

\section{$\bullet \bullet$ A good comparison of experimental methods that are used to measure nanoparticle sizes}

50. Bazylińska U. Rationally designed double emulsion process for co-encapsulation of hybrid cargo in stealth nanocarriers. Colloids Surf Sci. A. 2017; 532: 476-482. (doi:10.1016/j.colsurfa.2017.04.027)

51. Ramezanpour M, Leung SSW, Delgado-Magnero KH, et al. Computational and experimental approaches for investigating nanoparticle-based drug delivery systems. Biochim. Biophys. Acta-Biomembranes. 2016; 1858: 1688-1709. (doi:10.1016/j.bbamem.2016.02.028)

52. Zhang $X$, Cheng HB, Dong W, et al. Design and intestinal mucus penetration mechanism of core-shell nanocomplex. J Controlled Release. 2018; 272: 29-38. (doi:10.1016/j.jconrel.2017.12.034)

53. Kobes JE, Daryaei I, Howison CM, et al. Improved treatment of pancreatic cancer with drug delivery nanoparticles loaded with a novel AKT/PDK1 inhibitor. Pancreas. 2016; 45: 1158-66. (doi:10.1097/mpa.0000000000000607) 
54. Toman P, Lien CF, Ahmad Z, et al. Nanoparticles of alkylglyceryl-dextran-graft-poly(lactic acid) for drug delivery to the brain: Preparation and in vitro investigation. Acta Biomater. 2015; 23: 250-62. (doi:10.1016/j.actbio.2015.05.009)

55. Ping Y, Ding DW, Ramos R, et al. Supramolecular beta-sheets stabilized protein nanocarriers for drug delivery and gene transfection. ACS Nano. 2017; 11: 4528-41. (doi:10.1021/acsnano.6b08393)

56. Masarudin MJ, Cutts SM, Evison BJ, et al. Factors determining the stability, size distribution, and cellular accumulation of small, monodisperse chitosan nanoparticles as candidate vectors for anticancer drug delivery: application to the passive encapsulation of C-14-doxorubicin. Nanotechnol Sci Appl. 2015; 8: 67-80. (doi:10.2147/nsa.s91785)

57. Al-Kinani AA, Naughton DP, Calabrese G, et al. Analysis of 2-oxothiazolidine-4-carboxylic acid by hydrophilic interaction liquid chromatography: application for ocular delivery using chitosan nanoparticles. Anal Bioanal Chem. 2015; 407: 2645-50. (doi:10.1007/s00216-015-8494-8)

58. Akanda MH, Rai R, Slipper IJ, et al. Delivery of retinoic acid to LNCap human prostate cancer cells using solid lipid nanoparticles. Int J Pharm. 2015; 493: 161-71. (doi:10.1016/j.ijpharm.2015.07.042)

59. Cai XJ, Woods A, Mesquida P, et al. Assessing the potential for drug-nanoparticle surface interactions to improve drug penetration into the skin. Mol Pharm. 2016; 13: $1375-84$. (doi:10.1021/acs.molpharmaceut.6b00032)

60. Engelhardt KH, Pinnapireddy SR, Baghdan E, et al. Transfection studies with colloidal systems containing highly purified bipolar tetraether lipids from sulfolobus acidocaldarius. Archaea. 2017: 8047149. (doi:10.1155/2017/8047149)

61. Briuglia ML, Rotella C, McFarlane A, et al. Influence of cholesterol on liposome stability and on in vitro drug release. Drug Del Transl Res. 2015; 5: 231-42. (doi:10.1007/s13346-015-0220-8)

- A valued source describing the influence of cholesterol on liposomes for the development of advanced nanosystems.

62. Meng L, Deng ZT, Niu LL, et al. A disposable microfluidic device for controlled drug release from thermalsensitive liposomes by high intensity focused ultrasound. Theranostics. 2015; 5: 1203-13. (doi:10.7150/thno.12295)

63. Roma-Rodrigues C, Fernandes AR, Baptista PV. Exosome in tumour microenvironment: overview of the crosstalk between normal and cancer cells. Biomed Res Int. 2014: 179486. (doi:10.1155/2014/179486)

64. Parisse P, Rago I, Severino LU, et al. Atomic force microscopy analysis of extracellular vesicles. Eur Biophys J Biophys Lett. 2017; 46: 813-20. (doi:10.1007/s00249-017-1252-4)

\section{- A good section on immobilisation strategies of extracellular vesicles for AFM imaging.}

65. Bourkoula E, Mangoni D, lus T, et al. Glioma-associated stem cells: a novel class of tumor-supporting cells able to predict prognosis of human low-grade gliomas. Stem Cells. 2014; 32: 1239-53. (doi:10.1002/stem.1605)

66. Skog J, Wurdinger T, van Rijn S, et al. Glioblastoma microvesicles transport RNA and proteins that promote tumour growth and provide diagnostic biomarkers. Nature Cell Biol. 2008; 10: $1470-6$. (doi:10.1038/ncb1800)

67. Svensson KJ, Kucharzewska P, Christianson HC, et al. Hypoxia triggers a proangiogenic pathway involving cancer cell microvesicles and PAR-2-mediated heparin-binding EGF signaling in endothelial cells. Proc Natl Acad Sci USA. 2011; 108: 13147-52. (doi:10.1073/pnas.1104261108)

68. Akers JC, Ramakrishnan V, Kim R, et al. MiR-21 in the extracellular vesicles (EVs) of cerebrospinal fluid (CSF): A platform for glioblastoma biomarker development. PLoS ONE. 2013; 8: e78115. (doi:10.1371/journal.pone.0078115) 
69. Fais S, O'Driscoll L, Borras FE, et al. Evidence-based clinical use of nanoscale extracellular vesicles in nanomedicine. ACS Nano. 2016; 10: 3886-99. (doi:10.1021/acsnano.5b08015)

70. Gardiner C, Di Vizio D, Sahoo S, et al. Techniques used for the isolation and characterization of extracellular vesicles: results of a worldwide survey. J Extracellular Vesicles. 2016; 5: 32945. (doi:10.3402/jev.v5.32945)

71. Bousmail D, Amrein L, Fakhoury JJ, et al. Precision spherical nucleic acids for delivery of anticancer drugs. Chem Sci. 2017; 8: 6218-29. (doi:10.1039/c7sc01619k)

72. Arora D, Kumar A, Gupta P, et al. Preparation, characterization and cytotoxic evaluation of bovine serum albumin nanoparticles encapsulating 5-methylmellein: A secondary metabolite isolated from Xylaria psidii. Bioorg Med Chem Lett. 2017; 27: 5126-30. (doi:10.1016/j.bmcl.2017.10.064)

73. Fojtu M, Chia XY, Sofer Z, et al. Black phosphorus nanoparticles potentiate the anticancer effect of oxaliplatin in ovarian cancer cell line. Adv Funct Mater. 2017; 27: 1701955. (doi:10.1002/adfm.201701955)

74. Paul PK, Treetong A, Suedee R. Biomimetic insulin-imprinted polymer nanoparticles as a potential oral drug delivery system. Acta Pharm. 2017; 67: 149-68. (doi:10.1515/acph-2017-0020)

75. Fatouros DG, Lamprou DA, Urquhart AJ, et al. Lipid-like self-assembling peptide nanovesicles for drug delivery. ACS Appl Mater Interfaces. 2014; 6: 8184-9. (doi:10.1021/am501673x)

76. Grant CA, Twigg PC, Baker R, et al. Tattoo ink nanoparticles in skin tissue and fibroblasts. Beilstein J Nanotechnol. 2015; 6, 1183-91. (doi:10.3762/bjnano.6.120)

77. Smith J.R, Breakspear S, Campbell S.A. AFM in surface finishing: Part II. Surface roughness. Trans IMF. 2003; 81: B55-8

- A detailed description of surface roughness in relation to AFM.

78. Kim SY, Naskar D, Kundu SC, et al. Formulation of biologically-inspired silk-based drug carriers for pulmonary delivery targeted for lung cancer. Sci Reports. 2015; 5: 11878. (doi:10.1038/srep11878)

79. Perli MD, Karagkiozaki V, Pappa F, et al. Synthesis and characterization of Ag nanoparticles for orthopaedic applications. Mater Today-Proc. 2017; 4: 6889-900

80. Shimpi NG, Jha M. Green synthesis of silver nanoparticles using tabernaemontana divaricata and invitro cytotoxicity investigation against human lung adenocarcinoma. Int J Pharm Sci Res. 2017; 8: 5100-10. (doi:10.13040/ijpsr.0975-8232.8(12).5100-10)

81. Kumar S, Singh SK. Fabrication and characterization of fibroin solution and nanoparticle from silk fibers of Bombyx mori. Particulate Sci Technol. 2017; 35: 304-13. (doi:10.1080/02726351.2016.1154908)

82. Marchetti M, Wuite GJL, Roos WH. Atomic force microscopy observation and characterization of single virions and virus-like particles by nano-indentation. Curr Opin Virol. 2016; 18: 82-88. (doi:10.1016/j.coviro.2016.05.002)

83. Reggente M, Passeri D, Angeloni L, et al. Detection of stiff nanoparticles within cellular structures by contact resonance atomic force microscopy subsurface nanomechanical imaging. Nanoscale. 2017; 9: 5671-6. (doi:10.1039/c7nr01111c)

84. Karagkiozaki V, Pappa F, Arvaniti $D$, et al. The melding of nanomedicine in thrombosis imaging and treatment: A review. Future Sci. 2016; 2: FSO113. (doi:10.4155/fso.16.3)

85. Karagkiozaki V, Logothetidis S, Kassavetis S, et al. Nanomedicine for the reduction of the thrombogenicity of stent coatings. Int J Nanomed. 2010; 5: 239-248. (doi:10.2147/IJN.S7596)

86. Karagkiozaki V, Logothetidis S, Kassavetis S, et al. Nanoscale characterization of biological and mechanical profile of carbon stent nanocoatings. Eur J Nanomed. 2009; 2: 14-21. (doi:10.1515/EJNM.2009.2.2.14) 
87. Karagkiozaki V, Logothetidis S, Lousinian S, et al. Impact of surface electric properties of carbon-based thin films on platelets activation for nano-medical and nano-sensing

applications. J Int Nanomed. 2008; 3: 461-469. (doi: 10.2147/IJN.S3607)

88. Gebril AM, Lamprou DA, Alsaadi MM, et al. Assessment of the antigen-specific antibody response induced by mucosal administration of a GnRH conjugate entrapped in lipid nanoparticles. Nanomed Nanotechnol Biol Med. 2014; 10: 971-9. (doi:10.1016/j.nano.2013.12.005)

\section{- A valuable source describing the nanomechanical characterisation of soft nanoparticles such as lipids.}

89. Bozzini B, D'Urzo L, Huo SJ, et al. ATR FTIR study of levellers for Cu electrodeposition from acidic sulphate solution. Trans IMF. 2008; 86: 41-50. (doi:10.1179/174591908x264383)

90. Lee KY, Jeong L, Kang YO, et al. Electrospinning of polysaccharides for regenerative medicine. Adv Drug Delivery Rev. 2009; 61: 1020-32. (doi:10.1016/j.addr.2009.07.006)

91. Sill TJ, von Recum HA. Electrospinning: Applications in drug delivery and tissue engineering. Biomaterials. 2008; 29: 1989-2006. (doi:10.1016/j.biomaterials.2008.01.011).

92. Joseph J, Patel RM, Wenham A, et al. Biomedical applications of polyurethane materials and coatings. Trans IMF. 2018; 96: 121-9. (doi:10.1080/00202967.2018.1450209)

93. Kaur N, Kumar V, Dhakate SR. Synthesis and characterization of multiwalled CNT-PAN based composite carbon nanofibers via electrospinning. SpringerPlus. 2016; 5: 483. (doi:10.1186/s40064-016-2051-6)

94. Janjic M, Pappa F, Karagkiozaki V, et al. Surface modification of endovascular stents with rosuvastatin and heparin-loaded biodegradable nanofibers by electrospinning. Int J Nanomed. 2017; 12: 6343-55. (doi:10.2147/ijn.s138261)

95. Vulpe S, Negroiu G, Nastase C, et al. PAN/PDLLA fibers with magnetic mineral nanoparticles insertion for controlled release of drugs. Romanian Reports Phys. 2014; 66: 693-703

96. Viana JFC, Carrijo J, Freitas CG, et al. Antifungal nanofibers made by controlled release of sea animal derived peptide. Nanoscale. 2015; 7: 6238-46. (doi:10.1039/c5nr00767d)

97. Tipduangta P, Belton P, Fabian L, et al. Electrospun polymer blend nanofibers for tunable drug delivery: the role of transformative phase separation on controlling the release rate. Mol Pharm. 2016; 13: 25-39. (doi:10.1021/acs.molpharmaceut.5b00359)

98. Barrientos IJH, Paladino E, Brozio S, et al. Fabrication and characterisation of drug-loaded electrospun polymeric nanofibers for controlled release in hernia repair. Int J Pharm. 2017; 517: 329-337. (doi:10.1016/j.ijpharm.2016.12.022)

\section{- A valuable source describing polymer-drug interactions using state-of-the-art techniques.}

99. Barrientos IJH, Paladino E, Szabo P, et al. Electrospun collagen-based nanofibres: A sustainable material for improved antibiotic utilisation in tissue engineering applications. Int J Pharm. 2017; 531: 67-79. (doi:10.1016/j.ijpharm.2017.08.071)

100. Jiang J, Chen GJ, Shuler FD, et al. Local sustained delivery of 25-hydroxyvitamin D-3 for production of antimicrobial peptides. Pharm Res. 2015; 32: 2851-62. (doi:10.1007/s11095-015-1667-5)

101. Brako F, Raimi-Abraham B, Mahalingam S, et al. Making nanofibres of mucoadhesive polymer blends for vaginal therapies. Eur Polym J. 2015; 70: 186-96. (doi:10.1016/j.eurpolymj.2015.07.006)

102. Wali A, Zhang YC, Sengupta $P$, et al. Electrospinning of non-ionic cellulose ethers/polyvinyl alcohol nanofibers: Characterization and applications. Carbohydrate Polym. 2018; 181: $175-82$. (doi:10.1016/j.carbpol.2017.10.070)

103. Dzamukova MR, Naumenko EA, Lvov YM, et al. Enzyme-activated intracellular drug delivery with tubule clay nanoformulation. Sci Reports. 2015; 5: 10560. (doi:10.1038/srep10560) 
Expert Opinion on Drug Delivery. Postprint version. Accepted 07/11/2018.

Doi:10.1080/17425247.2018.1546693

104. Mendes AC, Nikogeorgos N, Lee S, et al. Nanomechanics of electrospun phospholipid fiber. Appl Phys Lett. 2015; 106: 223108. (doi:10.1063/1.4922283) 